\title{
Digital Transformation in Facility Management (FM). IoT and Big Data for Service Innovation
}

\author{
Nazly Atta and Cinzia Talamo
}

\begin{abstract}
The latest innovations in Information and Communication Technologies (ICTs) along with the establishment of the new paradigms of Internet of Things (IoT) and Big Data Management are opening up innovative scenarios with respect to cognitive and decision making processes related to the management of the built environment. The novel availability of information offered by these digital technologies can lead to the definition of strategies aimed at significantly reducing management costs and improving building performance and service quality. Although this potential is now widely recognized by the various operators in the sector, experimentations have not yet led to a harmonization and standardization of procedures, processes and enabling technologies applications. The paper proposes strategies and tools for supporting the various FM operators in the choice and implementation of IoT technologies as well as in the management of Big Data and their sources, aiming at optimizing and innovating the current FM processes, models and services.
\end{abstract}

Keywords Facility management (FM) - Building management $\cdot$ Internet of things $(\mathrm{IoT}) \cdot \mathrm{Big}$ data $\cdot$ Information and communication technology $(\mathrm{ICT}) \cdot$ Information management $\cdot$ FM digitalization

\section{Information and Communication Technologies as Driver for Innovation of FM Sector}

The Facility Management (FM) sector is undergoing a profound transformation of practices, processes, tools and references due to the adoption of novel ICT (Information and Communication Technology) solutions which nowadays promise to improve the traditionally conceived FM processes, making new knowledge bases available to support data-driven decision-making processes and embracing a network approach to stakeholder management. The digital transformation today is affecting the FM

N. Atta $\cdot$ C. Talamo $(\bowtie)$

Architecture, Built Environment and Construction Engineering-ABC Department, Politecnico di Milano, Milan, Italy

e-mail: cinzia.talamo@polimi.it 
sector and its operators that are trying to keep up with it, even if still in a convulsive way since there is a clear lack of consolidated and shared references and tools (Konanahalli et al. 2018). Indeed, the experimentations on ICT-FM integration are still at an infantile stage. However the operators of the FM sector already see the potential of technologies not only as mere tools but as generators of communication and collaboration opportunities able to increase their business value (Ahmed et al. 2017). In fact, when speaking about digital transformation, it is important to understand that it is not just a technological shift at the operational level, but it involves also the strategic level of the top management since it allows to create reliable knowledge bases concerning the several different aspects of the built environment allowing also new possibilities for a widespread continuous monitoring of relevant parameters (Talamo et al. 2016). Therefore, the recent technological innovations in the field of ICT should not be meant just as mere operational tools, but they have to be recognized as valuable sources of data and information, on which it is possible to improve management activities and to establish novel collaboration between company departments-deriving mutual benefits-and also to develop new business opportunities. In other words, the goal is no longer just to increase the operational efficiencywhich however remains an important objective for facility managers-but also to re-engineer processes, procedures and activities, thanks to the adoption of digital technologies. The role of the facility managers-who manage the so-called "no core business"- has always been to support the needs of the Client by ensuring a high quality of building services, the efficiency of the infrastructures and the promptness of interventions. However, in the last years we have witnessed a paradigm shift in the Facility Management sector: Clients increasingly require service strategies aimed at predicting events instead of responding to them. The market is asking companies for an increasingly pressing level of flexibility and innovation, forcing them to migrate from the widespread traditional culture of doing to new strategies aimed at predicting future trends (Konanahalli et al. 2018). This shift marks the transition from corrective or planned strategies to preventive and predictive strategies. These new demands, which today can be met and satisfied thanks to the integration of the new ICT solutions, lead facility managers to face profound changes in their traditional practices. Indeed, this new scenario requires a drastic rethinking of FM models, processes and services both at the strategic and operational levels, in order to meet the expectations of Clients, ensuring their competitiveness and increasing their added value. In such a frenetic and convulsive but also so challenging and exciting context, which marks this transitional period of digital transformation of the sector towards more advanced high-performance scenarios, the facility manager:

- can no longer be considered a mere maintenance or service manager, but must be able to rely on the tools of digitization-by gaining skills, know-how and experiences also related to the ICT field-in order to contribute to the development of the digital innovation of the FM sector;

- has important tasks and owns responsibilities related to several interconnected topics (as energy, security, quality of workplaces, data flow management, etc.) that need a constant and deep collaboration with all the company functions. Facility 
managers should ensure the horizontal collaboration among the different departments in charge of the different topics of interest by following a network approach rather than a siloed one, also relying on the new digital IoT platforms for communication and information sharing for identifying and exploiting possible synergies, sharing knowledge bases and deriving mutual benefits;

- must ride the wave of this digital transformation staying competitive and able to offer innovative cutting-edge FM services. Facility managers can reach this goal by experimenting and using the new technological tools enhancing their own capabilities of shaping innovative ideas, designing new FM solutions and fully implementing them anticipating Clients needs and expectations.

The common thread that links these aspects- today of vital importance for facility managers to promote and boost innovation-is the capacity of exploiting ICTs which represent the innovation factor that enables and supports this development and evolution of Facility Management. In particular, main important technological phenomena such as the Internet of Things (IoT), Big Data Management and Data Analytics are nowadays supporting the change of processes and functions of the facility management business (Fukada et al. 2018; Wong et al. 2018).

\section{FM-Related Information: The Role of IoT and Big Data Management}

ISO/IEC 20924:2018 Internet of Things (IoT)—Vocabulary ${ }^{1}$ defines Internet of Things (IoT) as an "infrastructure of interconnected entities, people, systems and information resources together with services which processes and reacts to information from the physical world and virtual world" (ISO/IEC 20924:2018). Therefore, the IoT can be meant as a network of connected devices (e.g. fixed, mobile and wearable sensors) that have communication functions (Lee and Kim 2018). The IoT is rapidly becoming one of the core technologies of the digital transformation of the FM sector because of its capability of connecting building users, building components and services merging the physical and virtual worlds and letting them communicating through intelligent digital interfaces. Moreover, the IoT increases the capabilities of facility managers to create updated knowledge bases - thanks to real-time sensor data-store them in the cloud and process data when needed through intelligent systems as the Information Platforms.

\footnotetext{
${ }^{1}$ The International Standard ISO/IEC 20924 Internet of Things (IoT)_Vocabulary has been prepared by the ISO/IEC Joint Technical Committee 1 (JTC1)_Information Technology and in particular by its sub-committee 41-Internet of Things and related technologies. The aim of this standard is to provide a definition of Internet of Things (IoT) along with the definitions of IoT-related terms and concepts, ensuring in this way a common and shared IoT terminology.
} 
In the IoT-based FM vision, sensors ${ }^{2}$ and IoT devices ${ }^{3}$ play a decisive role.

According to IoT Analytics (2018), the global IoT Market will reach $\$ 1,567 \mathrm{~B}$ by 2025. ${ }^{4}$ Statista (2019) forecasts that the amount of devices installed and connected to the Internet will arrive at 75.44 billion worldwide by $2025 .^{5}$ These forecasts confirm that the IoT, enabled by the already ubiquitous Internet technology, is a reality today. The technological revolution and digital transformation are already underway in the main social and business sectors with the promise of making the world a connected place. Sensors and IoT devices (e.g. wearables, smartphones, Radio-Frequency IDentification-RFID, smart meters, etc.) collect data-concerning the different aspect of the built environment — which are then analyzed and stored. In particular, sensors are embedded in/installed on physical objects (Things) and they are able to give to the physical objects communication and information exchange capabilities. Therefore, sensing technology is used to give to the objects virtual identities in order to acquire from them a broad range of data (e.g. relevant parameters of interest such as position, motion, etc.) (Konanahalli et al. 2018; Lee and Kim 2018) in the form of Big Data. According to the International Standard ISO/IEC 20546:2019 Information technology_Big data-Overview and vocabulary, ${ }^{6}$ the term Big Data ${ }^{7}$ implies datasets that are extensive in volume, velocity, variety and/or variability (Table 1).

Nowadays sensors and IoT devices - as well as traditional meters connected to a smart network which in this way gain communication capabilities - are able to collect FM-related parameters, in the form of Big Data, regarding — among others - for example, environmental conditions such as temperature, humidity, heat, atmosphere

\footnotetext{
${ }^{2}$ ISO/IEC 20924:2018 defines a sensor as an "IoT device that measures one or more properties of one or more physical entities and outputs digital data that can be transmitted over a network" (ISO/IEC 20924:2018).

${ }^{3}$ ISO/IEC 20924:2018 defines an IoT device as an "entity of an IoT system that interacts and communicates with the physical world through sensing or actuating" (ISO/IEC 20924:2018).

${ }^{4}$ Source: IoT Analytics 2018-available at: https://iot-analytics.com/state-of-the-iot-update-q1-q22018-number-of-iot-devices-now-7b/ (Accessed in April 2019).

${ }^{5}$ Source: Statista 2019-https://www.statista.com/statistics/471264/iot-number-of-connecteddevices-worldwide/ (Accessed in April 2019).

${ }^{6}$ The International Standard ISO/IEC 20546:2019 Information technology-Big data-Overview and vocabulary has been prepared by the Sub-committee SC 42-Artificial intelligence of the Joint Technical Committee ISO/IEC JTC 1-Information technology. The standard aims at providing a taxonomy, articulated in a set of terms and definitions, needed to promote the common understanding and the improved communication regarding the Big Data topic. Moreover, in order to reach a better understanding of the topic, the standard provides a conceptual overview of the Big Data field and of its relationship with other main technical areas and fields.

${ }^{7}$ ISO/IEC 20546:2019 defines Big Data as "extensive datasets—primarily in the data characteristics of volume, velocity, variety, and/or variability - that require a scalable technology for efficient storage, manipulation, management, and analysis" (ISO/IEC 20546:2019).
} 
Table 1 Big Data features. Adapted from Talamo and Atta (2018)

\begin{tabular}{|c|c|c|}
\hline "V" & Features & Description \\
\hline Volume & Data size and amounts & $\begin{array}{l}\text { Extensive amounts of Data (Petabyte, } \\
\text { Exabyte, etc.) available for performing } \\
\text { analysis to extract valuable information }\end{array}$ \\
\hline \multirow[t]{4}{*}{ Velocity } & Data in motion & $\begin{array}{l}\text { Fast data streams transmitted-through } \\
\text { communication networks-from one } \\
\text { source to one or more destinations }\end{array}$ \\
\hline & Data collection and storage & $\begin{array}{l}\text { Data streams instantly generated and, } \\
\text { then, collected and stored at high speed in } \\
\text { extremely fast times }\end{array}$ \\
\hline & Data lifetime & $\begin{array}{l}\text { Period of time in which data remain valid, } \\
\text { significant and reliable }\end{array}$ \\
\hline & Real-time data analysis & $\begin{array}{l}\text { Data can be extracted, aggregated, } \\
\text { processed and analyzed in real-time }\end{array}$ \\
\hline \multirow[t]{3}{*}{ Variety } & Heterogeneity of sources & $\begin{array}{l}\text { Possible sources: RFID tags, sensors, } \\
\text { databases, storage systems, logs or } \\
\text { accesses to public web, business } \\
\text { applications, social media, etc. }\end{array}$ \\
\hline & Typologies and shapes of data & $\begin{array}{l}\text { Possible data typologies and shapes: } \\
\text { images, video, audio, live streams, etc.; } \\
\text { information from databases and data } \\
\text { storage systems (e.g. SQL, NoSQL, doc } \\
\text { repository, etc.); digital documents (e.g. } \\
\text { txt, PDF, Excel, HTML, XML, etc.) }\end{array}$ \\
\hline & Diversity of data formats & $\begin{array}{l}\text { Possible data formats: structured data } \\
\text { (numeric, strings, alphanumeric); } \\
\text { semi-structured data (HTML and XML } \\
\text { files); unstructured data (free text, videos, } \\
\text { voice messages, images) }\end{array}$ \\
\hline \multirow[t]{3}{*}{ Variability } & Data semantic & $\begin{array}{l}\text { Change of data meaning according to the } \\
\text { reference context }\end{array}$ \\
\hline & Data format & Variable data structure/format/shape \\
\hline & Data quality & $\begin{array}{l}\text { Variable data interpretation according to } \\
\text { different users }\end{array}$ \\
\hline
\end{tabular}

composition, light, sound, etc. Being able to transmit data to a central monitoring system, connected ${ }^{8}$ sensors and devices can be used to remotely control the main building systems, such as air conditioning, heating, lighting, etc. Moreover, by combining external data coming from the surrounding urban environment-such as external temperature, external humidity, weather conditions, etc.- - with FM-related operational data it is possible to increase the capability of facility managers to better understand the impact of these surrounding external conditions on the building

\footnotetext{
${ }^{8}$ Networks (e.g. WPAN, Bluetooth, Wi-Fi, 3G, 4G, LTE, broadband network, Ethernet, etc.) connect the physical and the virtual world, enabling the possibility for people, things, and services to become connected, to communicate and to exchange data and information.
} 
service delivery. In this way, extending the detection to the urban scale (Table 2), it is possible to exploit interesting synergies and to increase the knowledge of external on-going phenomena that can influence-positively or negatively - the building and services performance (Barkham et al. 2018; Paganin et al. 2018). Indeed, for instance, the gained insights can be used to proactively plan resource requirements, increase response and organization skills and prevent possible issues according to the real-time external conditions (e.g. weather) and, above all, to the short-/long-term external conditions forecasts.

Table 2 Example of Urban Big Data. Adapted from Paganin et al. (2018)

\begin{tabular}{|c|c|c|}
\hline Urban Big Data & Sensors-generated data & Users-generated data \\
\hline \multirow[t]{7}{*}{ Possible sources } & $\begin{array}{l}\text { Connected systems of sensors } \\
\text { (e.g. WSN) and other IoT } \\
\text { networks in urban areas }\end{array}$ & Participatory sensing systems \\
\hline & Public utilities sensor systems & $\begin{array}{l}\text { Social media, blogging and } \\
\text { Web2.0 }\end{array}$ \\
\hline & $\begin{array}{l}\text { Building management } \\
\text { systems (BMS) }\end{array}$ & $\begin{array}{l}\text { Accesses and log-ins on web } \\
\text { applications }\end{array}$ \\
\hline & Smart grids & $\begin{array}{l}\text { Global positioning system } \\
\text { (GPS) }\end{array}$ \\
\hline & Surveillance system & $\begin{array}{l}\text { Global navigation satellite } \\
\text { systems (GNSS) }\end{array}$ \\
\hline & $\begin{array}{l}\text { Geographic information } \\
\text { systems (GIS) }\end{array}$ & On-line social networks \\
\hline & $\begin{array}{l}\text { Satellite earth observation } \\
\text { service }\end{array}$ & Mobile applications \\
\hline \multirow[t]{5}{*}{$\begin{array}{l}\text { Examples of types of Urban } \\
\text { Big Data }\end{array}$} & $\begin{array}{l}\text { Environmental data }(\mathrm{T}, \mathrm{H}, \mathrm{p} \text {, } \\
\text { etc.) }\end{array}$ & Users position \\
\hline & $\begin{array}{l}\text { Seismic, hydrological, and } \\
\text { geological data }\end{array}$ & Users preferences \\
\hline & $\begin{array}{l}\text { Data on mobility (delays in } \\
\text { public transport, real-time } \\
\text { traffic data, etc.) }\end{array}$ & Users online activities \\
\hline & $\begin{array}{l}\text { Data on public utilities } \\
\text { (distribution of energy, } \\
\text { electricity water, gas) }\end{array}$ & $\begin{array}{l}\text { Socially-generated or shared } \\
\text { data (posts, links, etc.) }\end{array}$ \\
\hline & $\begin{array}{l}\text { Data from monitoring of use } \\
\text { and consumption (heating, } \\
\text { lighting, etc.) }\end{array}$ & Replies to on-line surveys \\
\hline
\end{tabular}




\section{IoT Platforms for Advanced FM Service Management}

Sensors and devices — essential for collecting and extracting data from objects-are connected to terminal devices for data collection. It is necessary that these sensors are connected to the Internet which enables the data exchange communication functions. To exploit the potential of sensor data, it is also necessary to guarantee interoperability of Internet communication, an application system and an embedded system capable of providing user interfaces. These functions are performed by IoT platforms. The International Standard ISO/IEC 30141:2018 Internet of Things (loT)_Reference Architecture $^{9}$ provides a standardized IoT Reference Architecture highlighting six domains and related entities which communicate and exchange data by means of the network, as shown in Fig. 1.

In particular, the six domains of the IoT Platform identified by ISO/IEC 30141:2018 are (ISO/IEC 30141:2018):

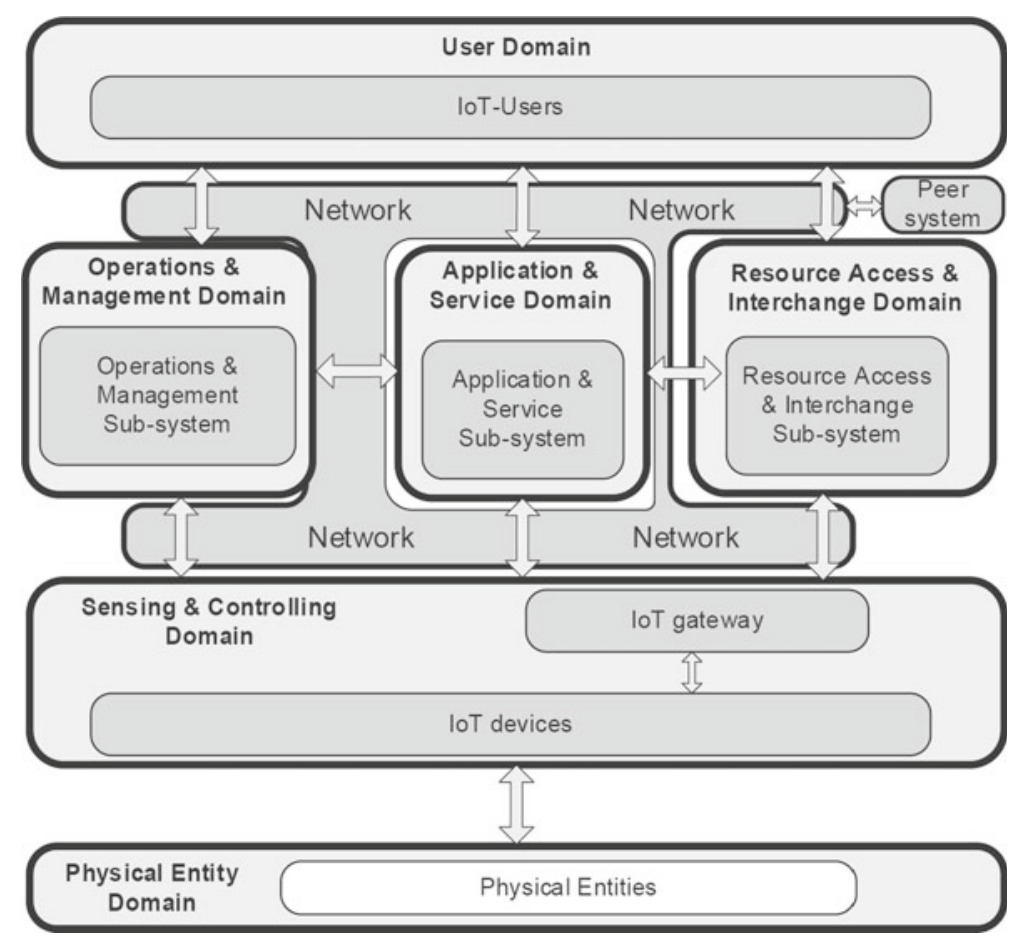

Fig. 1 Architecture of an IoT platform. Source ISO/IEC 30141:2018

\footnotetext{
${ }^{9}$ The International Standard ISO/IEC 30141 Internet of Things (loT)_Reference Architecture has been prepared by the sub-committee 41: Internet of Things and related technologies of the ISO/IEC Joint Technical Committee 1 (JTC1): Information technology. The standard proposes a general IoT Reference Architecture, including the definition of the system characteristics and its conceptual model.
} 
- User Domain (UD). In this domain the actors are human users who can interact with the offered digital services through user devices and applications, e.g. smartphones, tablets, computer desktops, dashboards, control panels, etc.

- Physical Entity Domain (PED). This is the domain of the physical entities (e.g. building elements, plants, equipments, etc.). It is the receiver of actions taken by facility managers based on the results of the sensing, monitoring, and controlling.

- Sensing and Controlling Domain (SCD). This is the domain of sensors, actuators, smart meters, etc. These IoT devices are able to collect information allowing a continuous monitoring of different aspects of the PED. This is a fundamental domain for facility managers (that can be in charge of this domain) who can collect, process, analyze and store data, exploiting data value for taking informed decisions and actions that can influence the physical entities of the PED.

- Operations and Management Domain (OMD). This is the domain of system operators and managers who have to maintain overtime the overall health of the systems of the whole IoT Platform.

- Resource Access and Interchange Domain (RAID). This domain gives to users the access to the capabilities of the IoT system, offered through smart service interfaces. The access can be different according to the different users (e.g. access to different functionalities, different authorities, etc.).

- Application and Service Domain (ASD). The main actors of this domain are the service providers, who offer applications and services to the IoT-User in the User Domain (UD). Moreover, the applications and services can also interact with the entities in the sensor, devices and actuators of the SCD in order to collect data and/or drive actions in the PED (ISO/IEC 30141:2018).

The IoT platform, therefore, enables the creation of new digital services, based on the possible interaction - thanks to smart interface applications-between people, things and services. Thus, the new services created and offered will be based on the convergence of data and services, using data collected through sensors and other heterogeneous data sources (Lee and Kim 2018). In particular, the platform allows facility managers to offer value-added services thanks to the new availability of real-time data, their processing, analysis, extraction and archiving as well as the contextualization, interpretation of on-going and future data, information and events, and the creation and analysis of alternative scenarios.

\section{Definition of FM IoT-Based Strategies}

With the aim of favoring data integration but also, above all, of allowing the integration and collaboration among FM stakeholders, nowadays the concept of IoT Platform is gaining more and more interest, being able to deliver a unique and integrated environment for the storage, analysis and retrieving of data and for an advanced management of services which embrace the concept of centralized data exploitation. In particular, IoT Platforms enable facility managers and real estate managers to 
benefit from an open IoT ecosystem that enables the integration of different technologies (building management systems, sensors, connectivity), making building management more intelligent. In particular, the IoT adoption allows to identify and implement new advanced strategies for FM operators. These strategies mainly refer to the following FM macro-areas of interest: a. Strategies for monitoring and controlling service performance; b. Operation and Maintenance strategies; c. Strategies for stakeholders management.

\subsection{Strategies for Monitoring and Controlling Service Performance}

The issue of monitoring the performance of FM services, thanks to the adoption of new technologies, is now based on two main topics: predictivity and control. Performance must be obtained and maintained through analysis, failure predictability and optimized and standardized processes as much as possible. Digital tools make it possible to make decisions through data that are beyond our perceptions, making us see real trends and allowing us to "anticipate" problems, even before we have to find them to solve them. The new frontier of real-time monitoring is represented by the centralized remote control and monitoring trough dynamic dashboards and visualization tools that show the collected sensor data on a user-friendly digital interface which allow facilities managers to observe at data to see in real-time exactly how employees and customers are using the building and its components and equipment. Indeed, the IoT enables to access in real-time data about several aspects of the building by easily controlling and monitoring the facility remotely. The data collected by the IoT allow facility managers to be more effective in preventing issues and reducing the time spent for "on site" inspections. This process has to be meant as circular and iterative, allowing a continuous improvement. In this way, the technological tools and intelligence can inform and improve facility management policies overtime, leading the FM industry forward.

\subsection{Operation and Maintenance Strategies}

The IoT application to the maintenance management allows to delineate new strategies, such as Condition-based and Predictive Maintenance, useful to contain costs, reduce the waste of resources and limit downtimes. These benefits can be achieved thanks to the continuous and dynamic monitoring of the state of operation and use of building components and plants. In particular, the maintenance strategies that recur in the traditional management practices of Operation and Maintenance are mainly the corrective maintenance and the planned preventive maintenance. Particularly, corrective maintenance is performed after the occurrence of a fault. This strategy often 
involves high costs, production downtimes and long intervention times and intervals. To overcome these issues, traditionally the scheduled preventive maintenance is used. It is performed at predetermined regular intervals, according to an established time schedule (calendar), in order to detect faults before they occur. However, usually in this case a high number of maintenance interventions is programmed independently of the condition of the building components themselves. This often involves execution of interventions on components that are not actually affected by degradation/failure and still far from the end of their useful life, with consequent increased maintenance costs. Instead, Operation and Maintenance IoT-based strategies allow:

- to promptly intervene when abnormal conditions exist, that could lead to a drop in performance, or situations of deterioration or failure of the component (Conditionbased Maintenance). In this way periodic on site inspections of building components conditions will be no longer needed (remote real-time monitoring) and interventions will be carried out according to the actual operating profile of the components, hence work orders will consequently be generated real-time. In this way, the maintenance activity will be aligned to the real and actual building needs avoiding unnecessary costs and limiting the use of resources;

- to predict the operating conditions of building components (Predictive Maintenance). Interventions will no longer be performed at regular and periodic intervals, but the frequencies will be defined using proper mathematical models useful to identify the time remaining before the failure. Therefore, the maintenance program is no more determined by a prescribed timeline but by analysis algorithms that use the data collected by IoT sensors in order to recognize in advance the occurrence of degradations, malfunctions or breakdowns, thus allowing to plan interventions in time, avoiding interference with on-going core activities.

By allowing facility managers to detect present trends and to forecast the values of the parameters of interest, making it possible to foresee the future behaviors of the building components, these new Operation and Maintenance strategies inform and support decision-making processes both at strategic and operational level.

\subsection{Strategies for Stakeholders Management}

The traditional FM practices are affected by the information silos approach, which is characterized by a lack of collaboration and information sharing between the different departments, as well as between the different stakeholders. Each department implements its own methods, procedures and tools to satisfy very specific operational requirements. Furthermore, these systems are often poorly implemented due to budget constraints and often suffer from a competitiveness aimed at demonstrating departmental efficiencies rather than global organizational ones. For example, different systems are often used to perform audits, plan maintenance, manage the help desk, track equipment, manage suppliers, check safety notices, organize cleaning, etc. This highly individual approach of the departments not only increases the 
complexity of the work but also the operating costs associated with these activities as well as the personnel training costs and administrative costs. IoT technology offers solutions aimed at overcoming this "data islands" sectorial approach that often leads to a supply of disconnected services and poor customer satisfaction. In particular, the IoT allows the creation of a connected ecosystem of people, devices and systems, in which it is possible to centrally manage the data, making the information bases of each department a common capital for all the departments and stakeholders. Thus, IoT has the potential to connect all the functional silos to make them horizontally integrated, favoring the stakeholders' engagement and collaboration and the integration of all the available knowledge bases. Moreover, the implementation of a widespread sensors network can detect data useful to different departments. If the IoT infrastructure, tools, methods and procedures are shared between departments and stakeholders - with a view to horizontal integration of tools, know-how and skills - it is possible to achieve considerable benefits also in terms of economic efficiency.

\section{References}

Ahmed V, Tezel A, Aziz Z, Sibley M (2017) The future of big data in facilities management: opportunities and challenges. Facilities 35(13/14):725-745

Barkham R, Bokhari S, Saiz A (2018) Urban big data: city management and real estate markets. New York, NY, USA, GovLab Digest

Fukada T, Huang W, Janssen P, Crolla K, Alhadidi S (2018) Field survey system for facility management using BIM model

Konanahalli A, Oyedele L, Marinelli M, Selim G (2018) Big data: a new revolution in the UK facilities management sector

Lee HJ, Kim M (2018) The Internet of Things in a smart connected world. In: Internet of Thingstechnology, applications and standardization. IntechOpen

Paganin G, Talamo C, Atta N (2018) Knowledge management and resilience of urban and territorial systems. TECHNE-J Technol Archit Environ 15:124-133

Talamo C, Atta N (2018) Invitations to tender for facility management services: process mapping, service specifications and innovative scenarios. Springer

Talamo C, Atta N, Martani C, Paganin G (2016) The integration of physical and digital urban infrastructures: the role of "Big data". TECHNE-J Technol Archit Environ 11:217-225

Wong JKW, Ge J, He SX (2018) Digitisation in facilities management: a literature review and future research directions. Autom Constr 92:312-326

\section{Standard and Laws}

ISO/IEC 20546:2019 Information technology—Big data—Overview and vocabulary

ISO/IEC 20924:2018 Internet of Things (IoT)—Vocabulary

ISO/IEC 30141:2018 Internet of Things (loT)—Reference Architecture 


\section{Websites}

IoT Analytics 2018. https://iot-analytics.com/state-of-the-iot-update-q1-q2-2018-number-of-iotdevices-now-7b/. Accessed April 2019

Statista (2019). https://www.statista.com/statistics/471264/iot-number-of-connected-devicesworldwide/. Accessed April 2019

Open Access This chapter is licensed under the terms of the Creative Commons Attribution 4.0 International License (http://creativecommons.org/licenses/by/4.0/), which permits use, sharing, adaptation, distribution and reproduction in any medium or format, as long as you give appropriate credit to the original author(s) and the source, provide a link to the Creative Commons license and indicate if changes were made.

The images or other third party material in this chapter are included in the chapter's Creative Commons license, unless indicated otherwise in a credit line to the material. If material is not included in the chapter's Creative Commons license and your intended use is not permitted by statutory regulation or exceeds the permitted use, you will need to obtain permission directly from the copyright holder. 